\title{
Motives of Students' Joining Master Program at Princess Alia University College/Al Balqa Applied University
}

\author{
Abdullah Eid Al Habahbeh ${ }^{1}$ \\ ${ }^{1}$ Princess Alia University College, Al Balqa Applied University, Jordan \\ Correspondence: Abdullah Eid Al Habahbeh, Princess Alia University College, Al Balqa Applied University, \\ Jordan. E-mail: morganiteinstitute@yahoo.com
}

Received: September 22, 2013 Accepted: October 25, 2013 Online Published: December 26, 2013

doi:10.5539/ies.v7n1p81

URL: http://dx.doi.org/10.5539/ies.v7n1p81

\begin{abstract}
This study aimed at knowing the motives of students' joining master program at Princess Alia University College/Al Balqa Applied University by the graduate students and a degree of their importance and succession, and to know whether these motives differed according to the variables of gender, specialization, age, and marital status. To achieve this goal, a questionnaire of two parts was developed: the first part consisted of personal information of a subject for the independent variables (gender, specialization, age, and marital status). The second part consisted of 25 items distributed on the following five fields: scientific motive, professional motive, psychological motive, social motive and economical motive with five items for each field. The questionnaire was applied on a study sample of 100 male and female students after having acceptable values of validity and reliability. The date was statistically analyzed by using means, standard deviations, T-test, and one way ANOVA. The results of the study showed that:
\end{abstract}

Motives behind students' joining master program were in descending sequence: scientific, professional, psychological, economic and social.

There were statistically significant differences at $(\alpha \leq 0.01)$ between the means of the motives, due to students' gender, in the field of psychology for female and in the field of social motive $(\alpha \leq 0.05)$ for females.

There were no statistically significant differences at $(\alpha \leq 0.05)$ between the means of the motives, due to age, specialization and marital status.

The study recommended that Al Balqa Applied University should take in mind motives of students' joining master program by choosing the appropriate programs to develop and improve current programs for master in order to evaluate their level of knowledge and behavior.

Keywords: motives, master program students

\section{Introduction}

The University is considered as a cultural educational and social institution that interacts with the social, economic, cultural, and political conditions of the community, where the university seeks to prepare young technical, administrative, intellectual and professional cadres, also it is interested in addressing and solving the problems of society. Moreover, the different conditions of a society may affect motives of students' enrollment university in determining the types and strength of these motives impact.

The circle of university education has become wider as well as the number of students enrollment increased, thus these motives of students varied, whenever the interest in the quality of master program and developing its outputs grow, the need to know the motives of students' enrollment in order to guide the behavior of students towards achieving the general objectives of higher education.

Knowing and analyzing the motives that led the students to enroll in higher education is the first step to know the desires of this behavior and its tendencies, and trying to direct it, thereby helping to modify and develop the educational process in order to improve its outcomes that leads to achieve the overall objectives; Knowing impulses leads to know the objectives set by students as joining the higher education and expect the benefits they may gain. These objectives are closely linked with the needs of the community and the needs of the labor market as well as the required professions since students recognize the needs of the community where they live (Omari, 
2005).

Motivation is considered as a hypothetical concept that interprets the behavior, we do not see the "motivation" in people physically, but we can feel it by people actions. Accordingly, the motivation refers to what you want to do but not what you can do.

Woolfolk (1990, p. 303) see that "motivation refers to internal processes seek to stimulate human behavior, and direct it towards some goal and maintain it."

Thus, motivation is a term used when describing the forces that affect and guide our behavior, we also use this term to explain the differences in the strength of behavior, so that severe levels of behavior indicate to a higher level of motivation, furthermore motivation is used to signify the continuity of behavior and its resistance to extinction. Strongly driven behavior will continue to occur despite its strength (Petri \& Goven, 2004).

There are multiple forms of humanitarian motives; there are motives that can be interpreted and understood through the biological basis of behavior such as hunger, thirst, sleep and sex, these motives are very important to maintain human survival and to keep his life going on. There are other motives which are also important; these motives are linked to psychological, cognitive, and social aspects, the most prominent of these motives are: achievement motivation, which means the pursuit of excellence, Cognitive motivation that refers to the person who is enjoying the forms of cognitive behavior, moreover, motivation of self-actualization that refers to human quest to reach the maximum level of abilities, and the attribution motivation which is interested in studying the reasons that make us take certain decisions in the process of daily events (Rimawi, 2006).

Studying students' motives to join the master program in Princess Alia University College can contribute to the planning of courses of this program, which in turn meet and achieve these motivations; it can also help in developing and improving methods and criteria for selecting students for the master program.

\subsection{Problem of the Study}

Princess Alia University College is the first college in Balqa Applied University, which launched the master program since the academic year 2001/2002. Two years later, some colleges started to launch the master program. The master program at Princess Alia University College included two education specializations: Talent and Creativity and Educational Psychology.

After passing of almost ten years on this program, it is natural that the college and university need to conduct a scientific study to reveal the students' motives to join this program in order to develop and improve methods and criteria for selecting students in this program.

As the university students are the direct beneficiaries of the educational process in the college, it was necessary to identify their views on the motives behind joining the master program.

\subsection{The Importance of the Study}

This study has a theoretical and practical value represented in the following points:

(1) Knowing the extent of motives effects to join the master program in the college according to the study variables (gender, specialization, age, marital status), which is expected that results of the study will add cognitive theoretical to human knowledge in the field of students' motives to join master program.

(2) The study and analysis of students' motives to join the master program contribute to develop the educational process and improve the quality of their inputs.

(3) To identify students' motives to join the master program, and how each of them is important to develop plans, courses and activities designed for students as well as improve the methods of their choice.

(4) Identifying the students' motives to join the master program will help officials at the university introduce new programs in line with students' wishes and the community's needs to new specializations.

(5) The fact that this study (within the limits of researcher's knowledge) is one of its kinds in BAU increases in importance of objectives which can be achieved in this study.

\subsection{Objectives of the Study}

The aim of this study is to investigate the students' motives to join the master program in Princess Alia University College/Balqa Applied University according to the students themselves in the second semester of the academic year 2012/2013 as well as the order of these important motives in the scientific, professional, psychological, social, and economic areas, and the impact of gender, specialization, age and marital status on these motives to join the master program. 


\subsection{Questions of the Study}

This study seeks to answer the following questions:

What are the students' motives to join the master program according to the degree of prevalence?

Are there any statistically significant differences in students' motives to join the master program due to the variable of gender (male, female)?

Are there any statistically significant differences in students' motives to join the master program due to the variable of specialization (talent and creativity, Educational Psychology)?

Are there any statistically significant differences in students' motives to join the master program due to the variable of age (less than 25 years old, 25-35 years, more than 35 years old)?

Are there any statistically significant differences in students' motives to join the master program due to the variable of marital status (single or married)?

\subsection{Determinants of the Study}

Generalizing the results of this study is linked to temporal, spatial and objectivity determinants as the following:

The study sample is limited to master students in Princess Alia University College/Balqa Applied University during the second semester of the academic year 2012/2013; master students in other colleges are not included.

The study assumes that students' responses to the questionnaire were valid and reliable.

\subsection{Procedural Definitions}

Motive: is the force that drives the individual to do something in order to achieve a certain goal (Woolfolk, 1990) the word motives used in this study means the scientific, professional, psychological, social and economic motives that drive students to join the master program. The procedural motive in this study means the degree that student get in the questionnaire prepared by the researcher.

\section{Previous Studies}

The study conducted by Mustafa (1995) aimed to identify students' motives to join the higher education programs at the University of Jordan (Masters and PhD). The study sample consisted of 328 master students and $29 \mathrm{PhD}$ students. The results of the study showed that the main motive for students' joining in higher education programs at the university pertained to scientific motive followed respectively by psychological, social, professional, economic and unemployment motives. The results also showed a significant difference in the field of psychological motivation in favor of females as well as significant differences in the faculty pertaining to the field of psychological motivation in favor of students of humanity faculties, as for the area of economic motivation; it was in favor of students of science faculties.

The results also showed that there are significant differences in the field of social psychological motivation for married students, and the area of unemployment for single students. Results of the study also pointed there are significant differences attributed to the place of residence in the area of psychological motivation in favor of students who live outside the city of Amman. The results of the study also showed there are significant differences due to age in the field of economic motivation and unemployment in favor of students whose ages are 25 years and below. Finally, the results of study showed there are no significant differences between students' motives to join higher education programs due to the level of income.

Subaihat (2003) also conducted a study to find out the students' motives to join the master program in Palestinian universities. The factors of gender, age, specialization, university, place of residence, job, marital status, and the level of income impact these motives. The study sample consisted of 429 male and female students from three universities which are the University of Birzeit, Al Najah National University, University of Jerusalem, the questionnaire of the research consisted of 68 items distributed on six areas of motivation which are: scientific, professional, psychological, social, economic, and unemployment areas.

The results of study showed that the motives of joining the master program were arranged by their strength as follows: professional, scientific, psychological, economic, unemployment, and social motives. Moreover, there are significant differences attributed to the variable of gender in the field of psychotherapy in favor of females. Furthermore, there are significant differences due to the variable of age according to the factor of unemployment in favor of younger students, and there were significant differences due to the variable of job in the field of psychology for the benefit of government job. As for the field of unemployment, it was in favor of students who do not have job, also there are significant differences for the variable of marital status for the professional, social, economic and unemployment motives in favor of single students, there were also significant differences due to 
the variable of income in the social, economic and unemployment motives in favor of low-income. There were no significant differences due to the variables of specialization and place of residence to all motives.

Omari (2005) also has conducted a study aimed to identify the students' motives to join the graduate studies among the students of Jordanian universities as perceived by graduate studies students, moreover this study aimed to identify the degree of importance of these motives in the psychological, cultural, social, scientific and economic fields, as well as the impact of each of the gender, age and academic level on these motives. The study sample consisted of 500 male and female graduate students of master program students (Higher Diploma, Masters and $\mathrm{PhD}$ ) in each of the University of Jordan, Yarmouk University, and Mutah University. The results showed that the motives to join the graduate studies were arranged in descending order as follows: psychological motive, cultural motive, scientific motive, economic motive, and social motive. The results of the study showed there are no statistically significant differences between the means for these motives due to the variables of gender, age or academic achievement.

Tanash (2007) has conducted a study aimed to identify the personal and professional objectives of students to join the official Jordanian universities, and the impact of each of the gender, college, university, the academic level of student, and the academic level of parents. The stratified random sample consisted of 953 male and female students from Jordan University, Yarmouk University, Technology University and Mutah University: the results of the study showed that most important personal objectives of students joining the universities are improving the daily lives through a better understanding of life, to develop their abilities to adapt to life, and to develop their personalities. While the professional objectives are: preparing for future work and developing technical skills and capacity in the field of labor. The study also showed that there are statistically significant differences between male and female students in the field of personal objectives to join the universities, these objectives are developing and refining personality as well as developing capacity to be independent in favor of male students, and the objective of developing leadership capacity in favor of females.

The results also showed there are statistically significant differences in professional leadership objectives of students in favor of females, the results also showed there are statistically significant differences in the professional objectives of students due to the variable of academic level as follows: the development of operational capabilities in the field of labor for the benefit of students in the third and fourth years. As for the objective of future work, it was for the benefit of students of the first and second years. The study results showed statistically significant differences in the personal objectives of student due to the variable of mother's level of education, these objectives pertain to develop and refine the personality as well as develop leadership abilities for the benefit of students whose mothers hold bachelor and above, while these statistically significant differences of the objective of developing capabilities to be independent for the benefit of students whose mothers have only secondary certificate, and the objective of developing moral values for the benefit of students whose mothers are illiterate, and the study showed there are significant differences in personal objectives for students due to the variable of academic faculty in favor of science faculties as well as humanitarian with the purpose of developing the personality and everyday life.

Harackiecz, Barron, and Elliot (1998) also stated the benefits of students' joining in graduate studies are various such as: satisfying self-actualization, strengthen self-confidence, to be accepted by others, to gain knowledge and necessary skills to work, and to avoid criticism of parents. According to a report submitted to the Council of Higher Education for the State of Oregon from the center of research and services (Office of Institutional Research Services, 2002) on the total objectives of higher education among students as follows: professional preparation in order to get a job by $46.8 \%$, to learn through distinguished education $28.2 \%$ to get a bachelor degree $25.5 \%$, to gain experience $8.2 \%$ to be able to support oneself $7.2 \%$ to meet the wishes of the self $6.6 \%$ to prepare for future life $4.5 \%$, to prepare for advanced teaching $3.6 \%$, for self - development $2.6 \%$, to have a better understanding for any reachable attitude $2.1 \%$, to meet new people $1.6 \%$, for social and artistic activities $0.7 \%$ and sports activities $0.5 \%$.

Hanen and Silver (2003) has conducted a study titled "innovations in teaching and learning of higher education" using a sample consisting of 1278 graduate male and female students and students from higher education in British universities, the study aimed to identify students' motives and choices to join the graduate studies. The results of the study also showed that the most important motives for the sample of the study was connected to a great degree with their desire to develop and improve their marketing practical dimensions and to respond to their professional motives, and the order of their motives are as follows:

(1) To get a better job.

(2) Continue a particular job which needs a specific qualification. 
(3) Interest in the subject of curriculum

(4) The desire to continue learning and education.

The results showed that there was no role for the variables of age, gender or social class according to the type of college or program. He also noted $86 \%$ of sample members wanted to develop new skills or existing ones, and $80 \%$ of them indicated they wished to widen their dimensions more, whereas $79 \%$ of them indicated they wanted to develop their intellectual standing, furthermore $73 \%$ of them indicated they wanted to meet new people.

A study conducted by Aboitze and Knox (2003) dealt with the objectives of university students according to the variables related to gender. personal objectives for female students to get a university education is more important and highly statistically than males; female student give great value for gaining good education much higher than male students, whereas male students care much about training and get a job rather than female students. A study by Malaka and Covington (2005) pointed that there is a relationship between a clear understanding of what is going on the lecture hall and the so-called gained behavior among up the students to achieve their life goals.

After reviewing the results of previous studies in the survey about the students' motives to join graduate studies programs at universities, it can be summarized as follows:

(1) Students' motives to join graduate studies programs at universities included psychological, practical, social, economic, and cultural fields in addition to the field of unemployment.

(2) All studies focused on motives order according to their importance for students.

(3) The list of Jordanian universities that conducted previous studies didn't include Balqa Applied University, so this study came to cover the shortfall

(4) most previous studies studied the impact of both gender and college on students' motives, and some other variables were added such as age, marital status, income level, place of residence, and level of parents education, hence, the current study studied the effect of each gender, age, specialization and marital status.

(5) It was clear the results of previous studies lack consistency of findings whether in the effect of studied variables or in the order of motives to join graduate studies which calls for new studies.

\section{The Study Method}

Research Design: it was used in this study descriptive search method, which is an appropriate to approach to answer study questions and clarify the nature of relationship between the variables, and detect differences in the students' motives of joining master program program depending on the different levels of independent study variables, and to know if these differences are significant.

A questionnaire has been designed especially to collect the necessary data to the research, including four independent variables and one dependent variable with five fields. The independent variables include the following:

(1) Gender with two levels: Male, Female.

(2) Specialization with two levels: the talent and creativity, educational psychology.

(3) Age with three levels: less than 25 years old, 25-35 years old, and more than 35 years.

(4) Marital status with two levels: single, married.

The dependent variable is the total number of motives, which is divided into five fields for students' motives, namely: The scientific field, the professional field, the psychological field, the social field, and the economic field.

\subsection{Population of the Study}

The study population consisted of all master students in Princess Alia University College/Al Balqa Applied University for the academic year 2012/2013, the number of students were 136, 62 of them are master students in educational psychology specialization, and 74 of them are master students in talent and creativity specialization. 
Table 1. The distribution of study population depending on variables of specialization and gender

\begin{tabular}{cccc}
\hline Specialization Gender & Education & Talent & Total \\
\hline Male students & 14 & 22 & $\mathbf{3 6}$ \\
Female students & 48 & 52 & $\mathbf{1 0 0}$ \\
Total & 62 & 74 & $\mathbf{1 3 6}$ \\
\hline
\end{tabular}

\subsection{Sample of the Study}

Mmembers of the study were chosen using the intentional sample of master students at the college of both specializations of educational psychology and talent and creativity. The unit of choice was a division not an individual. The study sample consisted of 100 male and female students, 33 of them are male students whereas 67 of them are female students, and thus the study sample consisted of $73.53 \%$ of study population.

Table 2 shows the distribution of the study sample depending on the variables of gender and specialization.

Table 2. Distribution of the study sample on gender and specialization

\begin{tabular}{cccc}
\hline Specialization Gender & Education & Talent & Total \\
\hline Male students & 13 & 20 & $\mathbf{3 3}$ \\
Female students & 34 & 33 & $\mathbf{6 7}$ \\
Total & 47 & 53 & $\mathbf{1 0 0}$ \\
\hline
\end{tabular}

\subsection{Study Tool}

After reviewing the questionnaires used in previous studies, such as:

Mustafa (1995) and Omari (2005), a new questionnaire was developed to measure the motives of students' joining master program. The questionnaire consisted of two parts; the first part contains data of the study's independent variables, namely: gender, specialization, age and marital status. The second part consisted of students' motives of joining master program, which is divided into five fields: the scientific field which includes five items, the professional field with five items, the psychological field with five items, the social field with five items, and the economic field with five items. Thus, the questionnaire consisted of twenty-five items.

Quintet Likert Scale was used to measure the answers as follows: (high agree, agree, I do not know, disagree, strongly disagree) with these degrees $4,3,2,1$, and 0 respectively.

\subsection{The Validity of Study Tool}

The questionnaire was displayed in its initial form to seven academic members from Princess Alia University College; these members are specialized in psychology education, special education and education management to express their views about the appropriateness of the items of fields, as well as to demonstrate the clarity of purpose and integrity of language.

After examining the observations of jury, some items were re-composed; some were replaced, and the items that arbitrators agreed upon by $80 \%$ stayed. Accordingly, the final form of the questionnaire was developed.

\subsection{Reliability of Study Tool}

The reliability coefficient was measured using the method of testing and re-testing on 33 male and female students from outside the study sample, the value of Pearson's correlation coefficient was 0.80 .

The reliability coefficient was measured using Cronbach's alpha method on the pilot sample of 33 students and the value was 0.83 . As shown above, that study tool is valid and reliable to be acceptable for the purposes of this study.

\subsection{Statistical Treatment}

To answer questions of the study, it was used the Statistical Package for the Social Sciences (SPSS) to conduct deductive, descriptive statistical analysis. This analysis included means, standard deviations for students' responses, as well as it was used the t-test for two independent samples and analysis of one way ANOVA. 


\section{Results of the Study and Discussion}

After applying the procedures of the study as well as the analysis of statistical data descriptively and analytically, the following results were shown according to the study questions.

First: the results related to the first question with discussion.

The first question of the study was: What are the motives of students' joining master program among college students according to prevalence?

To answer this question, the means and standard deviations were found out from the sample responses for each field of motivation as shown in Table 3.

Table 3. The means and standard deviations for each field of motives ranked according to their importance

\begin{tabular}{ccc}
\hline Field & Means & Standard deviation \\
\hline Scientific & 3.57 & 0.58 \\
Professional & 3.53 & 0.72 \\
Psychological & 3.36 & 0.76 \\
Economic & 3.23 & 0.93 \\
Social & 3.12 & 0.87 \\
\hline
\end{tabular}

As shown in Table 3, the strongest motive is the scientific one that prompted students to join master program.

When you examine the means of scores for the items of scientific motive, the item "The belief that seeking knowledge is a noble goal" and the item of "the desire to improve the level of thinking" are the most common.

Whereas the professional motive came in second rank, and the item "raise the level of efficiency at work" and "change field of work for better" are the most frequent.

The psychological motive was ranked in third place; the item "to achieve personal ambitions" and the item "increase the sense of complacency" are the top frequently. As for the economic motive, it came in fourth rank, where the item: improving the living conditions of family and "to improve the economic level of family" are the most common. Whereas the social motive was the last one which was in fifth rank, and the item "to achieve a top social center" followed by the item "community service in the best way" are the most frequent.

These results approximately agreed with the results of study (Mustafa, 1995), where the scientific field occupied the first rank of motives to join Jordanian universities followed by the psychological, social, professional, economic and unemployment.

However, the results of this study disagreed with the results of each of Subaihat (2003) and Omari (2005) where the scientific field ranked the second and third place respectively. Also the results of this study disagreed with Tanash (2007), where the personal and professional objectives of students focused on the social field by improving daily life, cope with life and develop the necessary skills at work, and these results also differed with the findings studies conducted by Harackiecz et al. (1998); Hanen and Silver (2003) and Office of Institutional Research Services (2002) which focused on the objectives of students' motives to join universities according to professional, psychological, professional, and economic development.

The difference in priority of students' motives for joining master program in most of these studies was due to the difference in conditions of social, professional and economic life for individual, times and places.

Second: The results related to the second question with the discussion.

The second question of the study was as follows: Are there statistically significant differences in the motives of students' joining the master program among college students due to the variable of gender (male, female)?

To answer this question, the means and standard deviations were measured for students' scores on different fields and the total score of the questionnaire, the test $\mathrm{T}$ was conducted on two independent samples where the results were identified in Table 4. 
Table 4. T-test Results of the differences between the motive fields according to the variable of gender

\begin{tabular}{|c|c|c|c|c|c|c|}
\hline \multirow{2}{*}{ Field of Motive } & \multicolumn{2}{|c|}{ Arithmetic Mean } & \multicolumn{2}{|c|}{ Standard and Deviation } & \multirow{2}{*}{$\begin{array}{c}\text { Value of } \\
\quad T\end{array}$} & \multirow{2}{*}{ Level of Significance } \\
\hline & Females (67) & Males (33) & Females (27) & Males (33) & & \\
\hline Scientific & 17.97 & 17.61 & 1.62 & 1.85 & 1.01 & 0.317 \\
\hline Professional & 17.88 & 17.12 & 1.91 & 2.48 & 1.69 & 0.095 \\
\hline Psychological & 17.98 & 15.94 & 2.19 & 3.26 & $3.72 * *$ & 0.000 \\
\hline Social & 16.06 & 14.64 & 2.78 & 2.99 & $2.35^{*}$ & 0.021 \\
\hline Economical & 16.18 & 16.12 & 2.99 & 3.66 & 0.08 & 0.933 \\
\hline Total & 86.07 & 81.42 & 8.21 & 9.41 & $2.54 *$ & 0.013 \\
\hline
\end{tabular}

*Significant at a level of $\propto=0.05$.

** Significant at a level of $\propto=0.01$.

It is clear that Table 4 indicates to the presence of statistically significant differences $(\alpha=0.05)$ for the social motive, and total scale of motives in favor of female students, and there is a statistically significant difference $(\alpha=0.01)$ for the psychological motive in favor of female students, the results didn't show statistically significant differences due to the variable of gender for the rest of motives.

This result can be explained that obtaining a graduate degree for females makes them psychologically stable and socially appreciated by members of the community who appreciate higher education.

The results of this study are consistent with the results of Mustafa (1995) and Subaihat (2003) in the field of psychological motive, moreover the study results are consistent with Tanash (2007) and Aboits and Knox (2003) in the field of personal objectives for the females to gain higher education to develop leadership abilities as well, Whereas the results of this study contradict with Hanen and Slime (2003) and Omari (2005) that these results are not affected by the variable of gender.

Third: Results for the third question with debate.

The third question was as follows: Is there a statistically significant difference in the motives of students' joining the master program among college students due to the variable of specialization (educational, talent)?

To answer this question, the mean and standard deviations were measured for students' scores on different fields and the total score of the questionnaire, the test $\mathrm{T}$ was conducted on two independent samples where the results were identified in Table 5.

Table 5. T-test Results of the differences between the motive fields according to the variable of specialization

\begin{tabular}{|c|c|c|c|c|c|c|}
\hline \multirow{2}{*}{ Field of motive } & \multicolumn{2}{|c|}{ Arithmetic Mean } & \multicolumn{2}{|c|}{ Standard Deviation } & \multirow{2}{*}{$\begin{array}{c}\text { Value of } \\
T\end{array}$} & \multirow{2}{*}{ Level of significance } \\
\hline & Talent (53) & Edu (47) & Talent (53) & Edu (47) & & \\
\hline Scientific & 18.11 & 17.55 & 1.63 & 1.75 & 1.66 & 0.101 \\
\hline Professional & 17.66 & 17.60 & 2.25 & 2.02 & 0.15 & 0.881 \\
\hline Psychological & 17.34 & 17.28 & 2.46 & 3.08 & 0.11 & 0.910 \\
\hline Social & 15.74 & 15.43 & 2.93 & 2.92 & 0.53 & 0.598 \\
\hline Economical & 16.53 & 15.74 & 3.28 & 3.12 & 1.22 & 0.226 \\
\hline Total & 85.38 & 83.60 & 9.57 & 7.97 & 1.00 & 0.318 \\
\hline
\end{tabular}


Table 5 shows the lack of a statistically significant effect of the variable of specialization in all fields of motives to join the master program among college students.

This result was maybe attributed to the content of the courses prescribed in specializations of educational psychology and talent and creativity of master's program in the faculty of education are close in general, in addition to the presence of about $40 \%$ of common courses involved in plans of the two specializations.

The results of this study agreed with the study of Subaihat (2003) that there are significant differences due to the variable of specialization, whereas the results disagreed with the findings of Mustafa (1995) study that there are significant differences due to the difference of college in the field of psychology motive in favor of students of humanity faculties and according to the economic field results showed that there statistically significant differences in favor of students of science faculties, this result also disagreed with the study of Tanash (2007) that there are statistically significant differences in the field of personal objectives of students to join universities due to the academic faculty in favor of students of science faculties aiming to develop the personality and developing everyday life in favor of students of humanity faculties.

Fourth: Results for the fourth question with discussion.

The fourth question of the study was: Are there any statistically significant differences in the motives of joining the master program among college students due to the variable of age (less than 25 years old, 25-35 years old, more than 35 years old)?

To answer this question: One way-ANOVA conducted the significant differences of arithmetic means in every field of students' motives and the total score on the questionnaire as shown in Table 6.

Table 6. One way-ANOVA Results of the differences among the motive fields according to the variable of age

\begin{tabular}{|c|c|c|c|c|c|c|}
\hline Factor & $\begin{array}{l}\text { Source of } \\
\text { Variation }\end{array}$ & $\begin{array}{c}\text { Sum of } \\
\text { Squares }\end{array}$ & $\begin{array}{l}\text { Degree of } \\
\text { Freedom }\end{array}$ & $\begin{array}{l}\text { Mean of } \\
\text { Squares }\end{array}$ & $\begin{array}{c}\text { Value } \\
\text { of } \\
F\end{array}$ & $\begin{array}{c}\text { Critical Value } \\
\text { of } F\end{array}$ \\
\hline \multirow{2}{*}{ Scientific } & $\begin{array}{l}\text { Between } \\
\text { group }\end{array}$ & 6.07 & 2 & 3.04 & \multirow{2}{*}{1.05} & \multirow{2}{*}{0.559} \\
\hline & $\begin{array}{l}\text { Within } \\
\text { groups }\end{array}$ & 280.68 & 97 & 2.89 & & \\
\hline \multirow{2}{*}{ Professional } & $\begin{array}{l}\text { Between } \\
\text { group }\end{array}$ & 16.06 & 2 & 8.03 & \multirow{2}{*}{1.79} & \multirow{2}{*}{0.321} \\
\hline & $\begin{array}{l}\text { Within } \\
\text { groups }\end{array}$ & 435.25 & 97 & 4.49 & & \\
\hline \multirow{2}{*}{ Psychological } & $\begin{array}{l}\text { Between } \\
\text { group }\end{array}$ & 8.85 & 2 & 4.43 & \multirow{2}{*}{0.58} & \multirow{2}{*}{0.776} \\
\hline & $\begin{array}{l}\text { Within } \\
\text { groups }\end{array}$ & 740.54 & 97 & 7.67 & & \\
\hline \multirow{2}{*}{ Social } & $\begin{array}{l}\text { Between } \\
\text { group }\end{array}$ & 44.67 & 2 & 22.34 & \multirow{2}{*}{2.72} & \multirow{2}{*}{0.154} \\
\hline & $\begin{array}{l}\text { Within } \\
\text { groups }\end{array}$ & 797.52 & 97 & 8.22 & & \\
\hline \multirow{2}{*}{ Economical } & $\begin{array}{l}\text { Between } \\
\text { group }\end{array}$ & 25.06 & 2 & 12.53 & \multirow{2}{*}{1.22} & \multirow{2}{*}{0.495} \\
\hline & $\begin{array}{l}\text { Within } \\
\text { groups }\end{array}$ & 998.37 & 97 & 10.29 & & \\
\hline \multirow{2}{*}{ Total } & $\begin{array}{l}\text { Between } \\
\text { group }\end{array}$ & 166.83 & 2 & 83.42 & \multirow{2}{*}{1.06} & \multirow{2}{*}{0.553} \\
\hline & $\begin{array}{l}\text { Within } \\
\text { groups }\end{array}$ & 7600.01 & 97 & 78.35 & & \\
\hline
\end{tabular}


Table 6 shows there are no statistically significant differences in all fields of motives of students' joining the master program due to the variable of age. By referring to the data of the sample members, it was found that the size of the individuals of the medium age class (25-35) years occupied $52 \%$ of the total sample size, while the size of the individuals of the smallest age class (less than 25 years) occupied $30 \%$ of the total sample size and the remaining $18 \%$ of the total sample size for the individuals of the greatest age class (more than 35 years). According to the given data the occupation of the individuals of the medium age class approximately half the total dsample size may explain the absence of statistically significant of the age variable on the motives of students joining the master program.

The results of this study agreed with the study of Omari (2005) and the study of Hanen and Silver (2003) which showed that there are no statistically significant differences between the means of motives of students' joining the master program due to the variable of age whereas the results of the study of (Mustafa, 1995) which showed that there statistically significant differences between the means of the motives to join master program due to the age variable in the fields of economic motivation and unemployment for younger students.

As for the study of Subaihat (2003), there are statistically significant differences in the motive unemployment in favor of younger students.

Fifth: Results on the fifth question and discussion.

The fifth question of the study as follows: Are there statistically significant differences in the motives of students' joining the master program due to the variable of marital status (single, married)?

To answer this question, the mean and standard deviations were measured for students' scores on different fields and the total score of the questionnaire, the test $\mathrm{T}$ was conducted on two independent samples where the results were identified in Table 7.

Table 7. T-test Results of the differences between the motive fields according to the variable of marital status

\begin{tabular}{|c|c|c|c|c|c|c|}
\hline \multirow{2}{*}{ Field of Motive } & \multicolumn{2}{|c|}{ Arithmetic Mean } & \multicolumn{2}{|c|}{ Standard Deviation } & \multirow{2}{*}{$\begin{array}{c}\text { Value of } \\
\mathbf{T}\end{array}$} & \multirow{2}{*}{ Level of Significance } \\
\hline & Single(60) & Married (40) & Single (60) & Married (40) & & \\
\hline Scientific & 17.82 & 17.90 & 1.79 & 1.58 & -0.24 & 0.812 \\
\hline Professional & 17.50 & 17.83 & 2.21 & 2.04 & -0.74 & 0.459 \\
\hline Psychological & 17.05 & 17.70 & 2.92 & 2.46 & -1.16 & 0.249 \\
\hline Social & 15.72 & 15.40 & 2.79 & 3.13 & 0.53 & 0.597 \\
\hline Economical & 16.28 & 15.97 & 3.22 & 3.25 & 0.47 & 0.641 \\
\hline Total & 84.37 & 84.80 & 8.57 & 9.37 & -0.24 & 0.821 \\
\hline
\end{tabular}

Table 7 shows the lack of statistically significant differences in all fields of the motives of students' joining master program among college students due to the variable of marital status.

The convergence ratios of singles and married respondents ( $60 \%$ of singles vs. $40 \%$ of married) may explain that there are no statistically significant difference between the means of motives of students' joining the master program variable due to the variable of marital status.

The result of the current study disagree with the study of Mustafa (1995) which showed there are no statistically significant differences in favor of married students in the field of psychological motive, and in the field of unemployment motive in favor of single students. This result disagrees with the study of Subaihat (2003) which showed a statistically significant difference in favor of single students for the variable marital status in the social, professional, economic, and unemployment motives.

\section{Recommendations}

In the light of the findings of this study, the researcher recommended the following:

(1) Recommending the officials in Al Balqa Applied University to know the motives of students' joining the master program in Princess Alia University College to develop a plan of this program to achieve the scientific, psychological, social and economic objectives and needs of students and community . 
(2) Since the study concluded that the main motive for students' joining the master program was a scientific one, the researcher recommends that the university needs to take into account strengthening the knowledge base of program.

(3) To conduct an extensive study to know the motives of students' joining the master program in all the faculties of Balqa Applied University.

\section{References}

Abowitz, D., \& Knox, D. (2003). Goal of College Students. Some Gender Differences. College Student Journal, $37,21-30$.

Hanen, A., \& Silver, H. (2003). Innovations in Teaching and Learning in Higher Education (Higher Education Studies, University of Playmonth, London).

Harackiecz, J., Barron, K., \& Elliot, A. (1998). Rethinking Achievement Goals: When are they Adaptive for $\begin{array}{llllll}\text { College Students and why } & \text { Educational Pschologist, } & 33, & 1-21 .\end{array}$ http://dx.doi.org/10.1207/s15326985ep3301_1

Malaka, A., \& Covington, M. (2005). Perceiving School Performance as Instrumental to Future Goal Attainment: Effects on Graded Performance. Contemporary Educational Psychology, 30, 60-80. http://dx.doi.org/10.1016/j.cedpsych.2004.04.001

Mustafa, I. (1995). Motivates of students' joining graduate studies in Jordanian public universities (Unpublished Master thesis, University of Jordan, Amman, Jordan).

Office of Institutional Research and Services. (2002). Where Have Oregons Graduates Gone? A Report to the Oregon State Board of Higher Education. Oregon University System, Eugane, Oregon.

Omari, B. (2005). Motivates of students' joining graduate studies in Jordanian public universities as seen by graduate students. Educational Sciences Studies, 32(1), 140-155.

Petri, H., \& Govern, J. (2004). Motivation: Theory, Research and Applications. Australia: Thomson-Wadsworth.

Rimawi, M. (2006). General Psychology. Amman, Dar Al maseera.

Subaihat, S. (2003). Motivates of students' joining graduate studies in Palestinian universities (Unpublished Master thesis, An-Najah National University, Nablus, Palestine).

Tanash, S. (2007). The personal and professional objectives of students to join the official Jordanian universities. Educational Sciences Studies, 34(2), 269-285.

Woolfolk, A. (1990). Educational Psychology. Englewood Ciffs, NJ: Printice-Hall.

\section{Copyrights}

Copyright for this article is retained by the author(s), with first publication rights granted to the journal.

This is an open-access article distributed under the terms and conditions of the Creative Commons Attribution license (http://creativecommons.org/licenses/by/3.0/). 